\title{
Adsorption and Reduction of Chromium(VI) from Aqueous Solution by Multiwalled Carbon Nanotubes
}

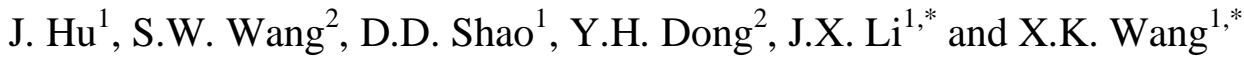 \\ ${ }^{I}$ Key Laboratory of Novel Thin Film Solar Cells, Institute of Plasma Physics, Chinese Academy of Sciences, P.O. Box \\ 1126, 230031, Hefei, P.R. China \\ ${ }^{2}$ School of Chemical Engineering, Shandong University of Technology, 255049, Zibo, P.R. China
}

\begin{abstract}
The adsorption of $\mathrm{Cr}(\mathrm{VI})$ on the raw multiwalled carbon nanotubes (MWCNTs) as a function of initial Cr(VI) concentration, $\mathrm{pH}$, temperature, and MWCNT dosage were studied. The removal of $\mathrm{Cr}(\mathrm{VI})$ from aqueous solution was dominated by adsorption of $\mathrm{Cr}(\mathrm{VI})$ and redox reaction of $\mathrm{Cr}(\mathrm{VI})$ to $\mathrm{Cr}(\mathrm{III})$. The adsorption of $\mathrm{Cr}(\mathrm{VI})$ decreased with increasing $\mathrm{pH}$ and increased with the rise in temperature and MWCNT dosage. The adsorption data of Cr(VI) on MWCNTs could be described well by Langmuir isotherm model. The thermodynamic values of Gibbs free energy ( $\Delta G^{\circ}$ ), enthalpy ( $\Delta H^{\circ}$ ), and entropy ( $\Delta S^{\circ}$ ) were calculated from temperature-dependent adsorption data, and the results indicated that the adsorption of $\mathrm{Cr}(\mathrm{VI})$ on the raw MWCNTs was a spontaneous process. The results suggest that MWCNTs are suitable materials in the preconcentration and solidification of $\mathrm{Cr}(\mathrm{VI})$ from large volume of solutions.
\end{abstract}

\section{INTRODUCTION}

Chromium is one of the extremely toxic heavy metals found in various industrial wastewaters [1]. It presents in the environment in two main oxidation states, i.e., $\mathrm{Cr}(\mathrm{III})$ and $\mathrm{Cr}(\mathrm{VI}) . \mathrm{Cr}(\mathrm{III})$ is an essential element in humans and is much less toxic than $\mathrm{Cr}(\mathrm{VI})$, which is recognized as a carcinogenic and mutagenic agent [2]. $\mathrm{Cr}(\mathrm{VI})$ usually exists in wastewater as oxyanions such as chromate $\left(\mathrm{CrO}_{4}{ }^{2-}\right)$ and dichromate $\left(\mathrm{Cr}_{2} \mathrm{O}_{7}{ }^{2-}\right)$ ions. The latter form is the most toxic [3]. EPA (Environmental Protection Agency) has set the maximum level of total chromium concentration allowed in drinking water at $0.1 \mathrm{mg} / \mathrm{L}$ [4]. The contamination of soil and water from chromium arises from various industry processes such as leather tanning, electroplating, manufacturing of dye, paint and metal processing [3].

The most common approach for $\mathrm{Cr}(\mathrm{VI})$ removal is through reduction of $\mathrm{Cr}(\mathrm{VI})$ to $\mathrm{Cr}(\mathrm{III})$, followed by $\mathrm{Cr}(\mathrm{III})$ precipitation under the alkaline conditions [5]. Other viable technologies include extraction, ultrafiltration, electrodialysis, reverse osmosis and adsorption technology. However, adsorption technology is considered as the most costeffective method to handle a large amount of aqueous solution with low concentration of $\mathrm{Cr}(\mathrm{VI})$. As one of the most promising techniques for the removal of chromium from industrial wastewaters, adsorption technology has been employed for many years and the effectiveness of various adsorbents (such as calcined $\mathrm{Mg}-\mathrm{Al}-\mathrm{CO}_{3}$ hydrotalcite, activated carbon, seaweed biosorbent, cactus leaves and rice husk) have been demonstrated [4, 5-9].

*Address correspondence to these authors at the Institute of Plasma Physics, Chinese Academy of Sciences, P.O. Box 1126, 230031, Hefei, P.R. China; Tel: +86-551-5591368; Fax: +86-551-5591310; E-mails: lijx@ipp.ac.cn, xkwang@ipp.ac.cn
Carbon nanotubes (CNTs) have attracted great attention since their discovery [10] because of their small sizes, large surface areas, unique hollow structures, high mechanical strength and remarkable electrical conductivities. According to the carbon atom layers on the sidewalls of the nanotubes, CNTs can be visualized as a sheet of graphite that has been rolled into a tube, and divided into single walled carbon nanotubes (SWCNTs) and multiwalled carbon nanotubes (MWCNTs) [11-14]. Our previous results suggested that the oxidized MWCNTs showed exceptional adsorption capability and high adsorption efficiency for the removal of $\mathrm{Ni}(\mathrm{II})$, Am(III) and Th(IV) from wastewater [15-17]. The oxidized MWCNTs may be promising materials in environmental pollution management.

Although the studies of metal ions adsorption on oxidized MWCNTs are available in many literatures, the investigation of raw MWCNTs in the removal of metal ions is still interesting because the oxidation treatment of MWCNTs needs a large amount of acids. Although the oxidation of MWCNTs generates large amount of oxygen-containing functional groups such as $-\mathrm{COOH}, \mathrm{C}-\mathrm{H},-\mathrm{COH}$ on the surfaces of oxidized MWCNTs, the oxidation process is itself an environmental pollution process because acid is used in the oxidation process and a large amount of water is needed in the water rinsing of oxidized MWCNT samples. Thereby, the study of the raw MWCNTs in the removal of heavy metal ions from large volume of solutions is still significant. The main objectives of this study are: (1) to characterize the surface properties of raw MWCNTs with acid-base titration; (2) to investigate the effects of $\mathrm{pH}$, temperature, initial $\mathrm{Cr}(\mathrm{VI})$ concentration, and MWCNT dosage on $\mathrm{Cr}(\mathrm{VI})$ adsorption; (3) to calculate the thermodynamic parameters $\left(\Delta G^{\circ}, \Delta H^{\circ}, \Delta S^{\circ}\right)$ of $\mathrm{Cr}(\mathrm{VI})$ adsorption on the raw MWCNTs; (4) to compare the removal ability of raw and oxidized MWCNTs; and (5) to predict the required amount of raw MWCNTs according to develop a single stage batch adsorbent design model. 


\section{EXPERIMENTATION}

\section{Adsorption Materials}

MWCNTs were prepared by using chemical vapor deposition (CVD) of acetylene in hydrogen flow at $760{ }^{\circ} \mathrm{C}$ using $\mathrm{Ni}-\mathrm{Fe}$ nanoparticles as catalysts $\left(\mathrm{Fe}\left(\mathrm{NO}_{3}\right)_{2}\right.$ and $\mathrm{Ni}\left(\mathrm{NO}_{3}\right)_{2}$ were treated by sol-gel process and calcinations to get $\mathrm{FeO}$ and $\mathrm{NiO}$, and then deoxidized by $\mathrm{H}_{2}$ to get $\mathrm{Fe}$ and $\mathrm{Ni}$ as catalysts). The as-grown MWCNTs (raw MWCNTs) were used directly in the experiments. Part of the samples was added into the solution of $3 \mathrm{M} \mathrm{HNO}_{3}$ to remove the hemispherical caps of the nanotubes [16]. Thus oxidized MWCNTs were also studied as a comparison.

The $\operatorname{Cr}(\mathrm{VI})$ solution used in the experiments was prepared by diluting a $100 \mathrm{mg} / \mathrm{L}$ potassium dichromate $\left(\mathrm{K}_{2} \mathrm{Cr}_{2} \mathrm{O}_{7}\right)$ solution into deionized water to obtain the desired $\mathrm{Cr}(\mathrm{VI})$ concentration. All chemicals used in the experiments were purchased in analytical purity, and used without further purification.

\section{Batch Adsorption Experiments}

All the experiments were carried out under ambient conditions. The stock suspensions of MWCNTs and $\mathrm{NaClO}_{4}$ solution were equilibrated for 2 days, and then the stock solution of $\mathrm{Cr}(\mathrm{VI})$ was added in the polyethylene tubes to achieve the desired concentration of different components by using batch technique. The temperature control was provided by the water bath shaker units. The $\mathrm{pH}$ values of the suspensions were adjusted by adding negligible volumes of 0.1 or $0.01 \mathrm{M} \mathrm{HClO}_{4}$ or $\mathrm{NaOH}$. All the experimental data were the averages of duplicate determinations. The relative errors of the data were about $5 \%$.

After the suspensions were stirred for 165 hours, the solid phase was separated from the solution by ultracentrifugation method (18000 rpm for $40 \mathrm{~min}$ ) under controlled temperature to the adsorption experiments, and then the supernatant was filtered using $0.45 \mu \mathrm{m}$ membrane filters for analysis of the supernatant. The amount of adsorbed $\mathrm{Cr}(\mathrm{VI})$ were calculated as follows:

$$
q=\left(C_{0}-C_{t}\right) \times \frac{V}{m}
$$

where $q(\mathrm{mg} / \mathrm{g})$ is the amount of adsorbed $\mathrm{Cr}(\mathrm{VI})$ onto MWCNTs, $C_{0}(\mathrm{mg} / \mathrm{L})$ the initial $\mathrm{Cr}(\mathrm{VI})$ concentration, $\mathrm{C}_{t}$ the $\mathrm{Cr}(\mathrm{VI})$ concentration after a certain period of time $\mathrm{t}, V(\mathrm{~L})$ the volume of the suspension, and $m(\mathrm{~g})$ is the mass of MWCNTs.

\section{Analytical Methods}

The concentration of $\mathrm{Cr}(\mathrm{VI})$ was analyzed by spectrophotometry at wavelength of $540 \mathrm{~nm}$ by using diphenylcarbazide as chromogenic reagent, $0.2 \mathrm{~mol} / \mathrm{L} \mathrm{H}_{2} \mathrm{SO}_{4}$ and $0.1 \mathrm{~mol} / \mathrm{L}$ $\mathrm{H}_{3} \mathrm{PO}_{4}$ as buffering agent at $\mathrm{pH}$ maintained to $0.67 \pm 0.01$. The morphology of raw MWCNTs was analyzed by using TM (FEI Sirion-200) and the functional groups on the surface of samples for the Fourier transform infrared spectrometer (FT-IR) measurement were mounted on a Bruker EQUINOX55 spectrometer in a $\mathrm{KBr}$ pellet at room temperature.

\section{THEORETICAL CALCULATION}

\section{Removal Percent (\%) and Distribution Coefficient $\left(K_{d}\right)$}

The removal percent $(\%)$ is calculated by using the equation:

Removal $\%=\frac{C_{0}-C_{e}}{C_{0}} \times 100 \%$

where $C_{0}$ is the initial concentration of $\mathrm{Cr}(\mathrm{VI})$ in suspension and $C_{\mathrm{e}}$ is the equilibration concentration of $\mathrm{Cr}(\mathrm{VI})$ in supernatant after centrifugation.

The distribution coefficient $\left(K_{\mathrm{d}}\right)$ is regarded as a standard parameter in the assessment of the physicochemical behavior of metal ions between solid and liquid phases. It can be calculated by the following equation:

$$
K_{d}=\frac{C_{0}-C_{e}}{C_{e}} \times \frac{V}{m}
$$

\section{Adsorption Isotherms}

Adsorption isotherm models are used to describe experimental adsorption data. The model parameters and the underlying thermodynamic assumptions of these adsorption models can provide some insight into the sorption mechanism, the surface properties and affinity of the adsorbent. Therefore, obtaining the "best-fit" isotherm is very important.

\section{Langmuir Isotherm}

The Langmuir model was first used to describe the adsorption of gas molecules onto metal surface [18]. However, this model has been used successfully in many other processes. It is represented as follows [19]:

$\eta=\frac{q_{\mathrm{e}}}{q_{\mathrm{m}}}=\frac{K_{L} \cdot C_{\mathrm{e}}}{1+K_{\mathrm{L}} \cdot C_{\mathrm{e}}}$

where $\eta$ is the fraction of the surface coverage, $q_{\mathrm{e}}(\mathrm{mg} / \mathrm{g})$ and $C_{\mathrm{e}}(\mathrm{mg} / \mathrm{L})$ are the amount of adsorbed adsorbate per unit weight of adsorbent and the remained adsorbate concentration in solution. $q_{\mathrm{m}}(\mathrm{mg} / \mathrm{g})$ and $K_{L}(\mathrm{~L} / \mathrm{mg})$ are Langmuir constants related to adsorption capacity and energy of adsorption. Eq. (4) can be linearized by inversion to obtain the following form:

$\frac{C_{\mathrm{e}}}{q_{\mathrm{e}}}=\frac{1}{K_{\mathrm{L}} \cdot q_{\mathrm{m}}}+\frac{C_{\mathrm{e}}}{q_{\mathrm{m}}}$

\section{Freundlich Isotherm}

The Freundlich isotherm model can be applied to nonideal adsorption on heterogeneous surfaces as well as multilayer sorption. The model has the following form [20]:

$q_{e}=K_{F} \cdot C_{e}^{n}$

Eq. (6) can be rearranged as:

$\ln q_{e}=\ln K_{F}+n \ln C_{e}$

where $K_{\mathrm{F}}\left(\mathrm{mg}^{1-1 / n} \mathrm{~L}^{1 / n} \mathrm{~g}^{-1}\right)$ relates to adsorption capacity and $n$ $(0<n<1)$ to adsorption intensity. For $n=1$, the partition be- 
tween the two phases is independent of the concentration. The situation $n<1$ is the most common and corresponds to a normal L-type Langmuir isotherm, while $n>1$ is indicative of a cooperative sorption, which involves strong interactions between the molecules of adsorbate [3].

\section{Dubinin-Radushkevich (D-R) Isotherm}

The $D-R$ isotherm model is valid at low concentration ranges and can be used to describe adsorption on both homogeneous and heterogeneous surfaces [21]. The $D-R$ equation has the general expression:

$q=q_{m} \cdot e^{-\beta \varepsilon^{2}}$

or in the linear form:

$\ln q=\ln q_{m}-\beta \varepsilon^{2}$

where $q_{m}(\mathrm{mmol} / \mathrm{g})$ is the $D-R$ monolayer capacity, $\beta$ $\left(\mathrm{mol}^{2} / \mathrm{kJ}^{2}\right)$ is the constant related to the adsorption energy, and $\varepsilon$ is the Polanyi potential, which equals to:

$\varepsilon=R T \ln \left(1+1 / C_{e}\right)$

where $R$ is ideal gas constant $(8.314 \mathrm{~J} /(\mathrm{mol} \cdot \mathrm{K}))$, and $T$ is the absolute temperature in Kelvin (K). The constant $\beta$ gives the adsorption free energy, $E(\mathrm{~kJ} / \mathrm{mol})$, which is defined as the free energy change required to transfer $1 \mathrm{~mol}$ of ions from solution to the solid surface [22]. The relation is as the following:

$E=\frac{1}{\sqrt{2 \beta}}$

The magnitude of $E$ is useful for estimating the mechanism of the adsorption reaction. If $E$ is in the range of 8-16 $\mathrm{kJ} / \mathrm{mol}$, adsorption is governed by chemical ion exchange. In the case of $E<8 \mathrm{~kJ} / \mathrm{mol}$, physical forces may affect the adsorption. On the other hand, adsorption may be dominated by particle diffusion if $E>16 \mathrm{~kJ} / \mathrm{mol}[23,24]$.

\section{Adsorption Thermodynamics}

The thermodynamic parameters, i.e., the free energy change $\left(\Delta G^{\circ}\right)$, the enthalpy change $\left(\Delta H^{\circ}\right)$, and the entropy change $\left(\Delta S^{\circ}\right)$, for the adsorption of $\mathrm{Cr}(\mathrm{VI})$ on MWCNTs were calculated using the following equations:

$\ln K_{\mathrm{d}}=\Delta S^{\circ} / R-\Delta H^{\circ} / R T$

$\Delta G^{\circ}=\Delta H^{\circ}-T \Delta S^{\circ}$

The values of enthalpy change $\left(\Delta H^{\circ}\right)$ and entropy change $\left(\Delta S^{\circ}\right)$ were calculated from the slope and the intercept of the plot of $\ln K_{\mathrm{d}}$ vs. $1 / T$. The free energy change ( $\Delta G^{\circ}$ ) was determined from Eq. (13).

\section{RESULTS AND DISCUSSION}

\section{Characterization of MWCNTs}

The $\mathrm{N}_{2}$-BET surface area was measured to be $93.59 \mathrm{~m}^{2} / \mathrm{g}$. The TEM image (Fig. 1A) shows that the raw MWCNTs are curve and have cylindrical shapes with an external diameter of $10 \sim 30 \mathrm{~nm}$. The FT-IR spectrum of the raw MWCNTs (Fig. 1B) indicates that there are some oxygen-containing functional groups at the surfaces of MWCNTs. The peak at $3430 \mathrm{~cm}^{-1}$ is associated to $-\mathrm{OH}$ stretching mode. The peak at $2915 \mathrm{~cm}^{-1}$ may be the stretching vibration of $-\mathrm{CH}$ on the sidewalls. The peak at $1630 \mathrm{~cm}^{-1}$ may be the stretching band of $\mathrm{C}=\mathrm{C}$, and the peaks at 1095 and $1380 \mathrm{~cm}^{-1}$ may be associated to carboxylic groups.

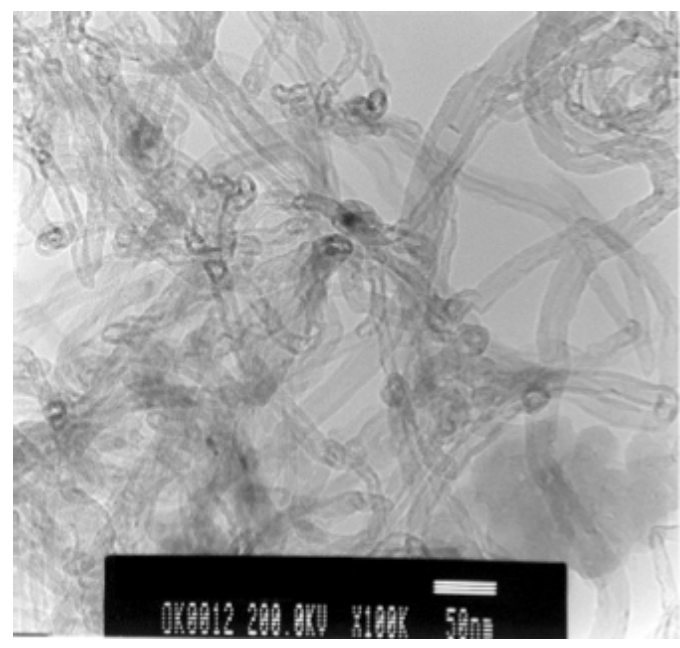

Fig. (1A). TEM image of raw MWCNT sample.

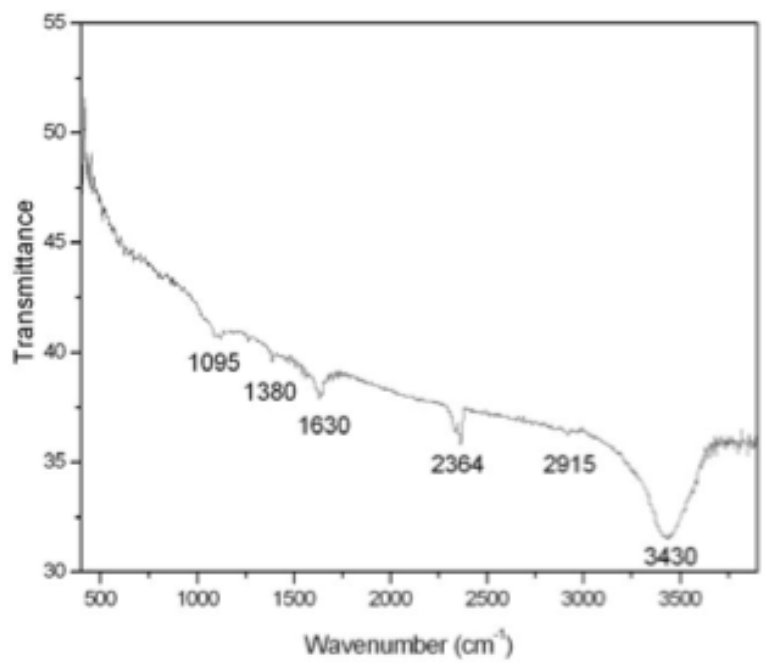

Fig. (1B). FTIR spectrum of raw MWCNT sample.

The acid-base titration data of raw MWCNTs are shown in Fig. (2A). TOTH is the total concentration of consumed protons in the titration process, which is calculated from the following equation:

TOTH $=\frac{-\left(V_{\mathrm{b}}-V_{\mathrm{eb} 1}\right) \cdot C_{\mathrm{b}}}{V_{0}+V_{\mathrm{b}}}$

where $V_{\mathrm{b}}$ is the volume of $\mathrm{NaOH}$ used in titration at each point; $V_{\mathrm{eb} 1}$ is the volume of $\mathrm{NaOH}$ used in titration at Gran point to zero on the acidic side; $V_{0}$ is the initial volume of the suspension; $C_{\mathrm{b}}$ is the concentration of $\mathrm{NaOH}$ used in the acid-base titration. 


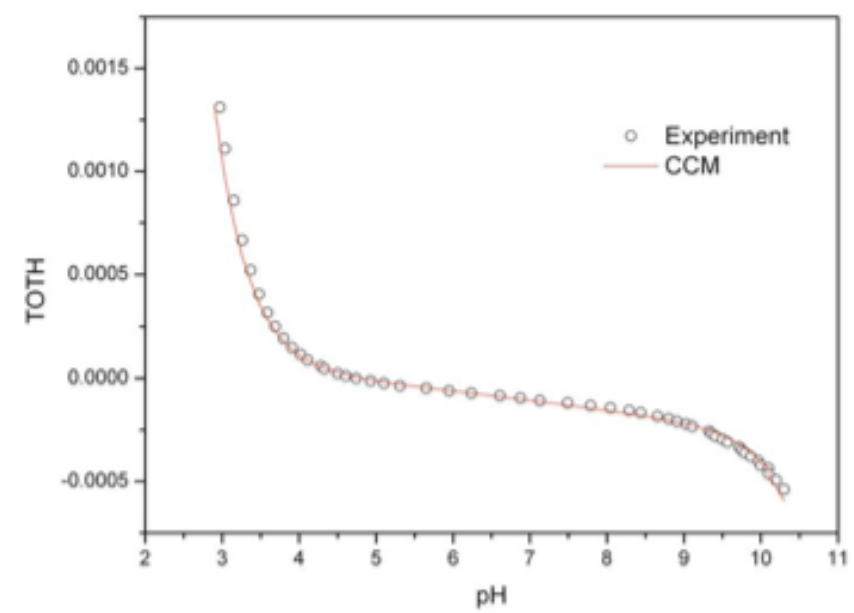

Fig. (2A). Acid-base titration of raw MWCNTs $\mathrm{I}=0.01 \mathrm{M} \mathrm{NaClO}$ and $\mathrm{T}=20{ }^{\circ} \mathrm{C}$. The line represents model calculation based on the CCM with the aid of FITEQL 3.2.

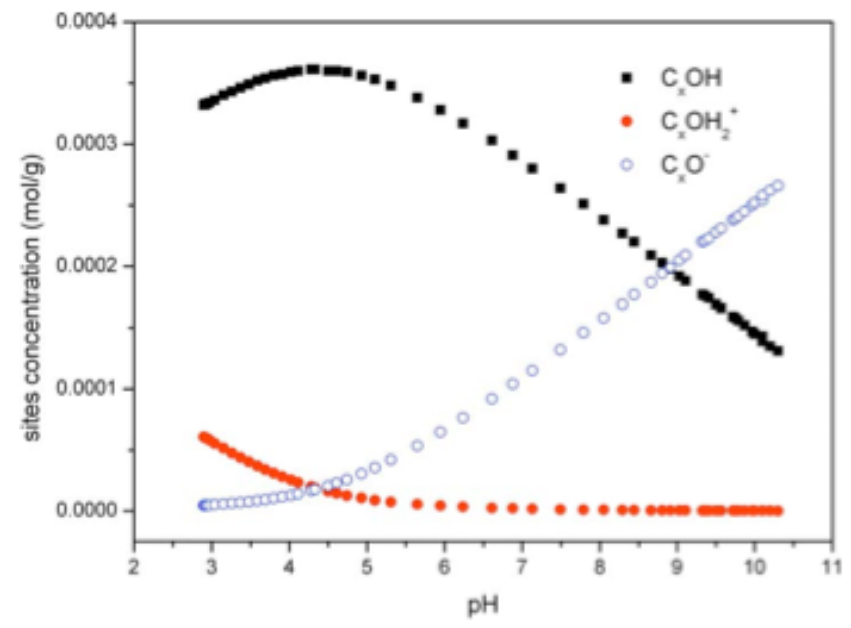

Fig. (2B). Distribution of surface site concentrations of MWCNTs $(5.0 \mathrm{~g} / \mathrm{L})$ as a function of $\mathrm{pH}$ at $\mathrm{I}=0.01 \mathrm{M} \mathrm{NaClO}_{4}$ and $\mathrm{T}=20^{\circ} \mathrm{C}$.

For experimental data modeling, various surface complexation models (SCMs) have been developed and extensively utilized to interpret and to predict the interfacial procedures. The commonly adopted forms include the diffusion layer model (DLM), the constant capacitance model (CCM) and the triple layer model (TLM) $[25,26]$. In the aqueous medium, the solid surface is used to characterize hydroxyl groups which exhibit amphoteric behavior. Accordingly, the surface protonation and deprotonation reactions can be expressed as:

$\mathrm{C}_{x} \mathrm{OH}+\mathrm{H}^{+}=\mathrm{C}_{x} \mathrm{OH}_{2}^{+}$

$\mathrm{C}_{x} \mathrm{OH}=\mathrm{C}_{x} \mathrm{O}^{-}+\mathrm{H}^{+}$

where $\mathrm{C}_{x} \mathrm{OH}_{2}^{+}, \mathrm{C}_{x} \mathrm{OH}$ and $\mathrm{C}_{x} \mathrm{O}^{-}$represent positively charged, neutral and negatively charged sites on the surface of raw MWCNTs, respectively. The distribution of these sites as a function of $\mathrm{pH}$ can be calculated from the acid-base titration with the aid of FITQEL 3.2 (Fig. 2B).
According to Fig. (2B), the site $\left(\mathrm{C}_{x} \mathrm{O}^{-}\right)$concentration increases with increasing $\mathrm{pH}$, whereas the site $\left(\mathrm{C}_{x} \mathrm{OH}_{2}^{+}\right)$ concentration decreases with $\mathrm{pH}$ increases. The positive surface charge of MWCNTs is found at $\mathrm{pH}<\sim 4.3$ (according to Fig. 2B) $\left(\mathrm{pH}_{\mathrm{pzc}}\right.$, i.e., point of zero charge). Li et al. [27] had ever measured the point of zero charge $\left(\mathrm{pH}_{\mathrm{pzc}}\right)$ of oxidized MWCNTs and found it to be about 5. We measured the $\mathrm{pH}_{\mathrm{pzc}}$ of oxidized MWCNTs to be $\sim 5$ in our previous paper [16]. Below the $\mathrm{pH}_{\mathrm{pzc}}$, the site $\left(\mathrm{C}_{x} \mathrm{OH}\right)$ concentration increases with increasing $\mathrm{pH}$, and then decreases with increasing $\mathrm{pH}$ at $\mathrm{pH}>\mathrm{pH}_{\mathrm{pzc}}$. The site density at the surfaces of raw MWCNTs calculated from the titration result is $0.397 \mathrm{mmol} / \mathrm{g}$. The consecutive acidity constants of $\mathrm{C}_{x} \mathrm{OH}$ sites of MWCNTs as $\mathrm{p} K_{\mathrm{a}}$ are optimized to be 3.076 for $\mathrm{C}_{x} \mathrm{OH}_{2}^{+}$, and -5.665 for $\mathrm{C}_{x} \mathrm{O}^{-}$with WSOS/DF $=16.41$ (the value of WSOS/DF below 20 indicates a reasonably good fit).

\section{Effect of MWCNT Dosage}

The adsorption of $\mathrm{Cr}(\mathrm{VI})$ on MWCNTs as a function of MWCNT dosage at $\mathrm{T}=20 \pm 1{ }^{\circ} \mathrm{C}$ and $\mathrm{pH}=2.05 \pm 0.02$, $2.88 \pm 0.02$ and $4.40 \pm 0.05$ are shown in Fig. (3). The removal percentage of $\mathrm{Cr}(\mathrm{VI})$ on MWCNTs increased with increasing MWCNT dosage at the three $\mathrm{pH}$ values. With increasing MWCNT dosage, the number of available sites for binding $\mathrm{Cr}(\mathrm{VI})$ increased, thereby resulted in the higher removal percentage of $\mathrm{Cr}(\mathrm{VI})$ at higher MWCNT dosage [28].

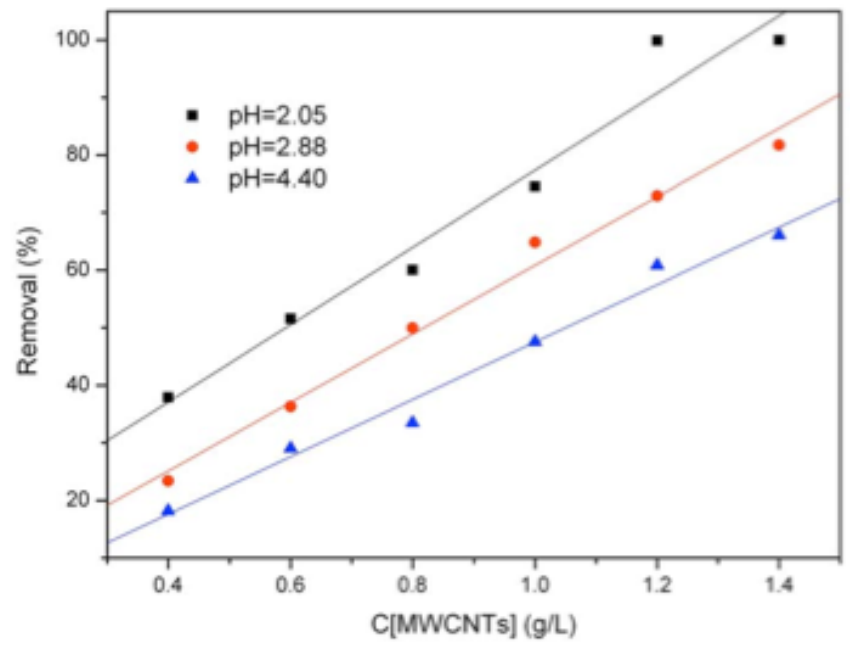

Fig. (3). Removal of $\mathrm{Cr}(\mathrm{VI})$ as a function of raw MWCNT content at different $\mathrm{pH}$ values. $\mathrm{C}[\mathrm{Cr}(\mathrm{VI})]_{\text {initial }}=3.0 \mathrm{mg} / \mathrm{L}, \mathrm{I}=0.01 \mathrm{M} \mathrm{NaClO}_{4}$, $\mathrm{T}=20 \pm 1^{\circ} \mathrm{C}$, contact time $=165 \mathrm{~h}$.

\section{Effect of $\mathrm{pH}$ and Temperature}

The adsorption of $\mathrm{Cr}(\mathrm{VI})$ from aqueous solution to the raw MWCNTs at three $\mathrm{pH}$ values $(\mathrm{pH}=2.05 \pm 0.02$, $2.88 \pm 0.02$ and $4.40 \pm 0.05$ ) and $\mathrm{T}=20 \pm 1{ }^{\circ} \mathrm{C}$ are shown in Fig. (4A). The contact time has been fixed to $165 \mathrm{~h}$ for all experiments. Fig. (4A) shows that the adsorption isotherm of $\mathrm{Cr}(\mathrm{VI})$ at $\mathrm{pH} 2.05$ is the highest and that of $\mathrm{Cr}(\mathrm{VI})$ at $\mathrm{pH}$ 4.40 is the lowest, which indicates that the adsorption of $\mathrm{Cr}(\mathrm{VI})$ decreases with increasing $\mathrm{pH}$. It is well known that 

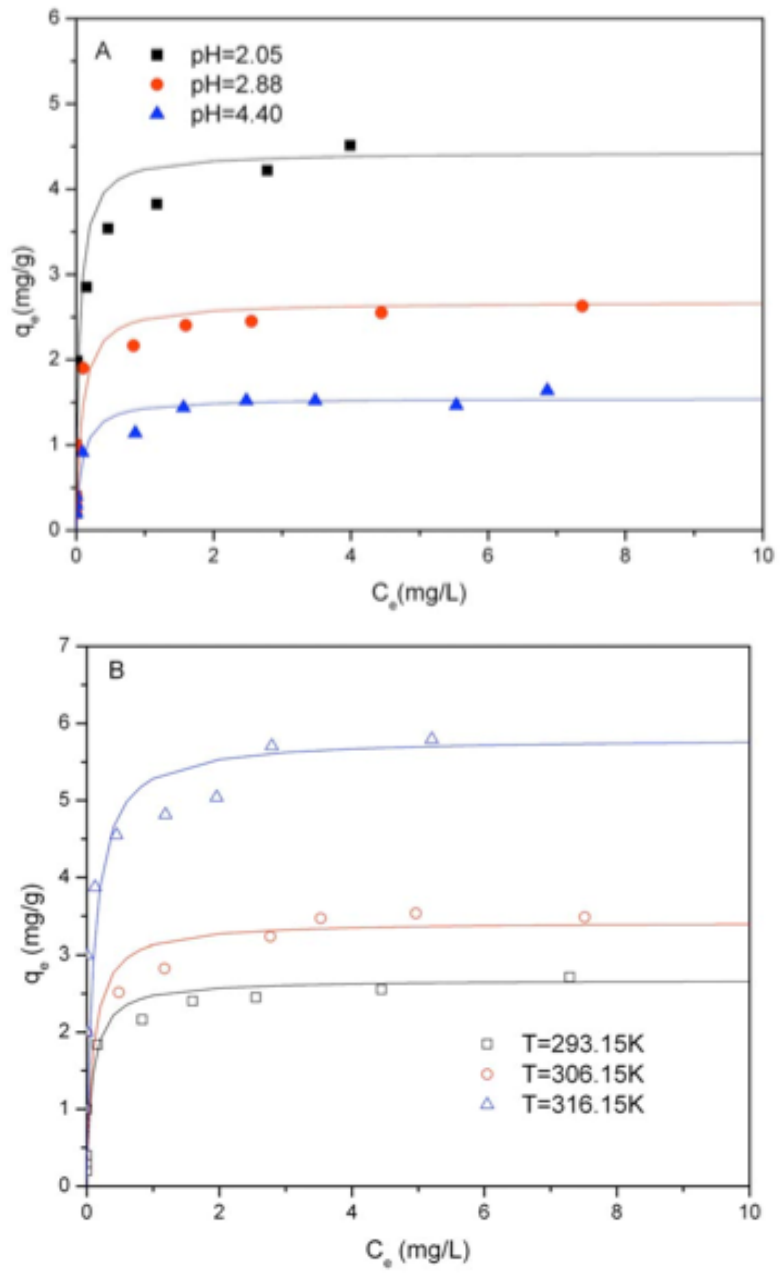

Fig. (4). Adsorption isotherms of $\mathrm{Cr}(\mathrm{VI})$ on raw MWCNTs. $\mathrm{I}=0.01 \mathrm{M} \mathrm{NaClO}$, m/V=1.0 g/L, and contact time $=165 \mathrm{~h}$. (A): at different $\mathrm{pH}$ values at $\mathrm{T}=20 \pm 10{ }^{\circ} \mathrm{C} ;(\mathbf{B})$ : at different temperatures at $\mathrm{pH}=2.88 \pm 0.02$.

$\mathrm{Cr}(\mathrm{VI})$ exists mainly in the form of $\mathrm{HCrO}_{4}{ }^{-}$at low $\mathrm{pH}$, and as $\mathrm{CrO}_{4}{ }^{2-}$ at high $\mathrm{pH}$ (Fig. 5) [4, 29, 30]. From the acid-base titration and FT-IR analysis, it is known that there are many functional groups, such as $-\mathrm{OH}$ and $-\mathrm{COOH}$ on the surfaces of MWCNTs. The surface sites $\left(\mathrm{C}_{x} \mathrm{OH}\right)$ can either be protonated to form $\mathrm{C}_{x} \mathrm{OH}_{2}^{+}$at low $\mathrm{pH}$ or be deprotonated to form $\mathrm{C}_{x} \mathrm{O}^{-}$at high $\mathrm{pH}$. It is clear that negatively charged $\mathrm{HCrO}_{4}^{-}$and $\mathrm{Cr}_{2} \mathrm{O}_{7}{ }^{2-}$ are easily to be adsorbed to the positively charged MWCNTs at low pH values due to the electronic attraction. The electrostatic repulsion between negative $\mathrm{Cr}(\mathrm{VI})$ species and negatively charged MWCNTs increased with increasing $\mathrm{pH}$ values at $\mathrm{pH}>\mathrm{pH}_{\mathrm{pzc}}$, and thereby resulted in the decrease of the adsorption of $\mathrm{Cr}(\mathrm{VI})$ on MWCNTs at $\mathrm{pH}>\mathrm{pH}_{\mathrm{pzc}}$. $\mathrm{Cr}(\mathrm{VI})$ can be captured by adsorption and ion exchange on the weak acid surface groups or on the basal plane sites [2]. At low $\mathrm{pH}$ values, the $\mathrm{HCrO}_{4}{ }^{-}$and $\mathrm{Cr}_{2} \mathrm{O}_{7}{ }^{2-}$ ions can be reduced to $\mathrm{Cr}$ (III) on the occurrence of redox reactions between the surface groups [31]:

$$
\begin{aligned}
& 3 \mathrm{C}_{x} \mathrm{OH}+\mathrm{Cr}_{2} \mathrm{O}_{7}^{2-}+4 \mathrm{H}^{+}=3 \mathrm{C}_{x} \mathrm{O}+\mathrm{HCrO}_{4}^{-}+\mathrm{Cr}^{3+}+3 \mathrm{H}_{2} \mathrm{O} \\
& 3 \mathrm{C}_{x} \mathrm{OH}+\mathrm{HCrO}_{4}^{-}+4 \mathrm{H}^{+}=3 \mathrm{C}_{x} \mathrm{O}+\mathrm{Cr}^{3+}+4 \mathrm{H}_{2} \mathrm{O}
\end{aligned}
$$

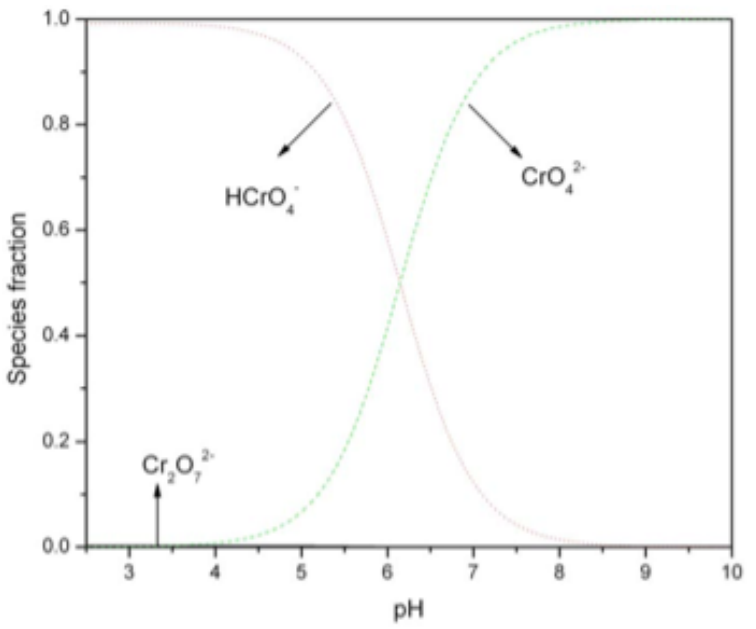

Fig. (5). The relative species of $\mathrm{Cr}(\mathrm{VI})$ in solution as a function of $\mathrm{pH}$ values.

where $C_{\mathrm{x}} O$ represents the functional groups of the MWCNT sites. The total $\mathrm{Cr}$ concentration in solution was measured and found that $\mathrm{Cr}$ was mainly in trivalent form at $\mathrm{pH} 2.05$ and 2.88 and $\mathrm{Cr}$ (III) cations accounted for about $30 \%$ of total $\mathrm{Cr}$ at $\mathrm{pH}$ 4.40. This means that $\mathrm{Cr}(\mathrm{VI})$ is reduced to $\mathrm{Cr}(\mathrm{III})$ in the presence of reducing substrate $\left(\mathrm{C}_{x} \mathrm{OH}\right)$ on the occurrence of redox reactions between the surface groups and $\mathrm{Cr}(\mathrm{VI})$ at low $\mathrm{pH}$ values. The results were very similar to the results reported by Di Natale et al. [2]. To further understand the removal mechanism of $\mathrm{Cr}(\mathrm{VI})$ on MWCNTs, the sample after the adsorption of $\mathrm{Cr}(\mathrm{VI})$ for 165 hours at $\mathrm{pH} 2.88$ was analyzed with X-ray photoelectron spectroscopy (XPS). XPS spectrum (Fig. 6) shows two $\mathrm{Cr} 2 \mathrm{p} 1 / 2$ and $\mathrm{Cr} 2 \mathrm{p} 3 / 2$ peaks that are respectively centered at $587.4 \mathrm{eV}$ and $577.3 \mathrm{eV}$, which are consistent with $\mathrm{Cr}(\mathrm{VI})$ and $\mathrm{Cr}(\mathrm{III})$ [5]. The XPS result also indicates that $\mathrm{Cr}$ are adsorbed on MWCNTs as $\mathrm{Cr}$ (III) and $\mathrm{Cr}(\mathrm{VI})$, which also suggests that part of adsorbed $\mathrm{Cr}(\mathrm{VI})$ is reduced to $\mathrm{Cr}(\mathrm{III})$.

It is well known that temperature is an important parameter in the adsorption process of metal ions. An increase in temperature is known to increase the diffusion rate of the adsorbate molecules across the external boundary layer and within the pores. Furthermore, the temperature changing may modify the equilibrium capacity of the adsorbent for a particular adsorbate [3]. The effect of temperature on the removal of $\mathrm{Cr}(\mathrm{VI})$ to MWCNTs was investigated at three temperatures $293.15 \pm 1 \mathrm{~K}, 306.15 \pm 1 \mathrm{~K}$ and $316.15 \pm 1 \mathrm{~K}$, respectively (Fig. 4B). The results show that the adsorption of $\mathrm{Cr}(\mathrm{VI})$ increases with increasing temperature.

\section{Comparison of Raw and Oxidized MWCNTs}

Fig. (7) shows the removal percentage of $\mathrm{Cr}(\mathrm{VI})$ on the oxidized and raw MWCNTs at different MWCNT dosages. The results show clearly that the removal percentage of $\mathrm{Cr}(\mathrm{VI})$ on the oxidized MWCNTs is higher than that of $\mathrm{Cr}(\mathrm{VI})$ on the raw MWCNTs. The amorphous carbon, carbon nanoparticles and catalyst particles, introduced by CVD preparation process, are removed during the oxidation process with $\mathrm{HNO}_{3}$. It is also well known that the oxidation process can generate not only a more hydrophilic surface structure, but also a large number of oxygen-containing func- 


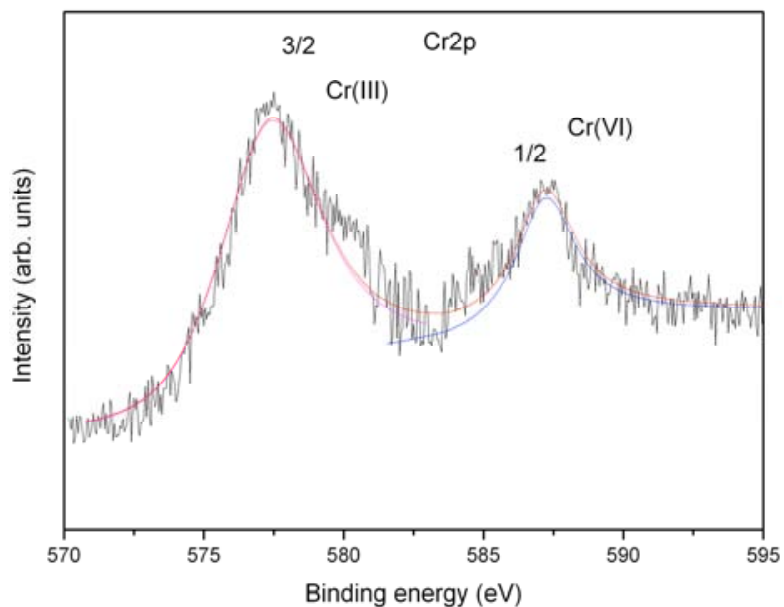

Fig. (6). XPS spectrum of MWCNT sample after $\mathrm{Cr}(\mathrm{VI})$ adsorption for $165 \mathrm{~h}$ at $\mathrm{pH}$ 2.88. The solid lines represent the $\mathrm{Cr}$ (III) and $\mathrm{Cr}(\mathrm{VI})$ components, and the fit envelope.

tional groups, which increases the ion-exchange capacity of carbon nanotubes [27]. These functional groups are also hydrophilic and make the oxidized MWCNTs to be dispersed more easily in water [32]. This also results in the higher removal percentage of $\mathrm{Cr}(\mathrm{VI})$ on the oxidized MWCNTs than that of $\mathrm{Cr}(\mathrm{VI})$ on the raw MWCNTs.

The distribution coefficients $\left(K_{\mathrm{d}}\right)$ of $\mathrm{Cr}(\mathrm{VI})$ on oxidized and raw MWCNTs as a function of $\mathrm{Cr}(\mathrm{VI})$ concentration are also shown in Fig. (7). The distribution coefficient $\left(K_{\mathrm{d}}\right)$ increases with increasing MWCNT content. With increasing solid content, the available sites for binding $\mathrm{Cr}(\mathrm{VI})$ increases and thereby enhances the adsorption of $\mathrm{Cr}(\mathrm{VI})$ from solution to solid. Another important interpretation is that the amount

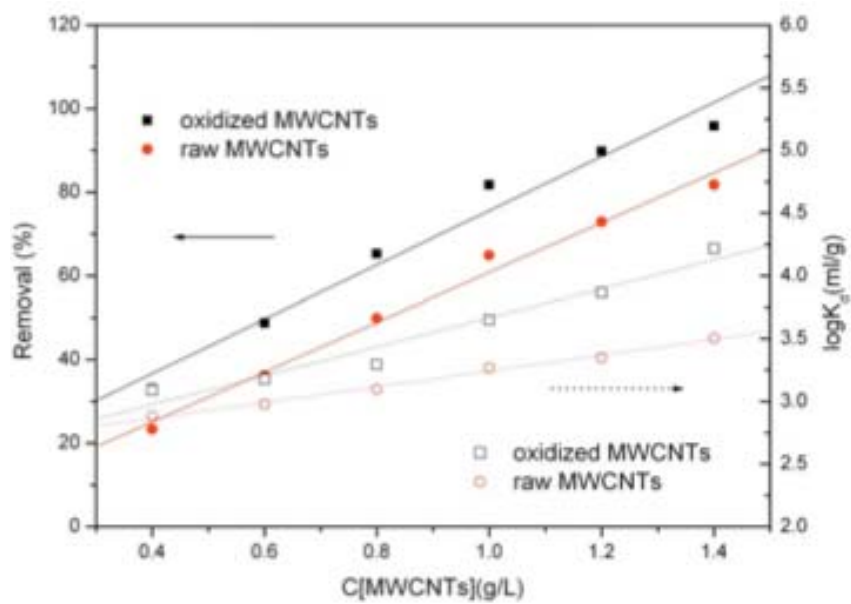

Fig. (7). Removal of $\mathrm{Cr}(\mathrm{VI})$ on the oxidized and raw MWCNTs as a function of MWCNT content. $\mathrm{C}[\mathrm{Cr}(\mathrm{VI})]_{\text {initial }}=3.0 \mathrm{mg} / \mathrm{L}, \mathrm{I}=0.01 \mathrm{M}$ $\mathrm{NaClO}_{4}, \mathrm{~T}=20 \pm 1^{\circ} \mathrm{C}$, contact time $=165 \mathrm{~h}, \mathrm{pH}=2.88 \pm 0.02$.

of $\mathrm{Cr}(\mathrm{VI})$ reduction to $\mathrm{Cr}(\mathrm{III})$ increases with increasing MWCNT dosage. In the experiments, the removal of $\mathrm{Cr}(\mathrm{VI})$ by adsorption of $\mathrm{Cr}(\mathrm{VI})$ and the reduction of $\mathrm{Cr}(\mathrm{VI})$ to $\mathrm{Cr}(\mathrm{III})$ were both taken into account. Thereby, it is reasonable that the $K_{\mathrm{d}}$ values increases with increasing MWCNT dosage.

\section{Adsorption Isotherm Model Analysis}

Three models, the Langmuir, Freundlich and D-R isotherms models, have been adopted for $\mathrm{Cr}(\mathrm{VI})$ adsorption on raw MWCNTs at different $\mathrm{pH}$ values and at different temperatures in the experiment. The relative parameters calculated from Eqs. (5, 7 and 9) are listed in Table 1. From the R

Table 1. The Parameters for Langmuir, Freundlich and D-R Models

\begin{tabular}{|c|c|c|c|c|c|c|}
\hline $\begin{array}{l}\text { Isothermal Model } \\
\text { Parameters }\end{array}$ & \multicolumn{3}{|c|}{$\mathbf{p H}$} & \multicolumn{3}{|c|}{$\mathbf{T}(\mathbf{K})$} \\
\hline$q_{\mathrm{m}}(\mathrm{mg} / \mathrm{g})$ & 4.434 & 2.679 & 1.551 & 2.679 & 3.427 & 5.811 \\
\hline$K_{\mathrm{L}}(\mathbf{L} / \mathbf{m g})$ & 20.80 & 12.08 & 11.64 & 12.08 & 10.53 & 10.01 \\
\hline \multicolumn{7}{|l|}{ Freundlich } \\
\hline$K_{\mathrm{F}}\left(\mathbf{m} \mathbf{g}^{1-1 / n} \mathbf{L}^{1 / n} \mathbf{g}^{-1}\right)$ & 3.735 & 2.224 & 1.230 & 2.224 & 2.790 & 4.860 \\
\hline$n$ & 0.146 & 0.101 & 0.138 & 0.101 & 0.153 & 0.108 \\
\hline$\beta\left(\mathbf{m o l}^{2} / \mathbf{k} \mathbf{J}^{2}\right)$ & $2.31 \times 10^{-3}$ & $2.23 \times 10^{-3}$ & $2.47 \times 10^{-3}$ & $2.23 \times 10^{-3}$ & $3.53 \times 10^{-3}$ & $2.18 \times 10^{-3}$ \\
\hline$q_{\mathrm{m}}(\mathrm{mol} / \mathrm{g})$ & $0.91 \times 10^{-3}$ & $0.53 \times 10^{-3}$ & $0.32 \times 10^{-3}$ & $0.53 \times 10^{-3}$ & $0.74 \times 10^{-3}$ & $1.16 \times 10^{-3}$ \\
\hline$E(\mathbf{k J} / \mathbf{m o l})$ & 14.74 & 15.07 & 14.43 & 15.07 & 11.92 & 15.40 \\
\hline$R^{2}$ & 0.990 & 0.977 & 0.96 & 0.97 & 0.96 & 0.930 \\
\hline
\end{tabular}


Table 2. The Thermodynamic Parameters of Cr(VI) Adsorption on MWCNTs at Different Cr(VI) Initial Concentrations

\begin{tabular}{|c|c|c|c|c|c|c|}
\hline \multirow{2}{*}{$\begin{array}{c}C_{0} \\
(\mathrm{~mol} / \mathrm{L})\end{array}$} & \multirow{2}{*}{$\begin{array}{c}\mathbf{T} \\
(\mathbf{K})\end{array}$} & \multirow{2}{*}{$\begin{array}{c}K_{\mathrm{d}} \\
(\mathrm{ml} / \mathrm{g})\end{array}$} & \multirow{2}{*}{$\frac{\Delta H^{\circ}}{\left(\mathbf{k J} \cdot \mathbf{m o l}^{-1}\right)}$} & \multirow{2}{*}{$\frac{\Delta S^{\circ}}{\left(\mathbf{k J} \cdot \mathrm{mol}^{-1} \cdot \mathbf{K}^{-1}\right)}$} & \multirow{2}{*}{$\frac{\Delta G^{\circ}}{\left(\mathbf{k J} \cdot \mathbf{m o l}^{-1}\right)}$} & \multirow{2}{*}{$\mathbf{R}^{2}$} \\
\hline & & & & & & \\
\hline \multirow[t]{3}{*}{$6.73 \times 10^{-5}$} & 293.15 & 573.71 & 48.96 & 0.219 & -15.25 & 0.935 \\
\hline & 306.15 & 982.89 & 48.96 & 0.219 & -18.10 & \\
\hline & 316.15 & 2571.16 & 48.96 & 0.219 & -20.29 & \\
\hline \multirow[t]{3}{*}{$9.62 \times 10^{-5}$} & 293.15 & 372.45 & 51.26 & 0.223 & -14.23 & 0.956 \\
\hline & 306.15 & 695.68 & 51.26 & 0.223 & -17.13 & \\
\hline & 316.15 & 1775.73 & 51.26 & 0.223 & -19.37 & \\
\hline
\end{tabular}

values, the adsorption isotherms can be simulated well by the three models. However, Langmuir model fits the data best in the three models, which suggests that the adsorption of $\mathrm{Cr}(\mathrm{VI})$ on MWCNTs mainly as monolayer on the sidewalls. The adsorption capacities $\left(q_{m}\right)$ decrease with increasing $\mathrm{pH}$ and increase with increasing temperature. The parameters $\left(K_{F}\right)$ of Freundlich model decrease with $\mathrm{pH}$ increasing and increase with increasing temperature. It is well known that $K_{F}$ is related to adsorption capacity, the values of $K_{F}$ are consistent with the values of $q_{m}$.

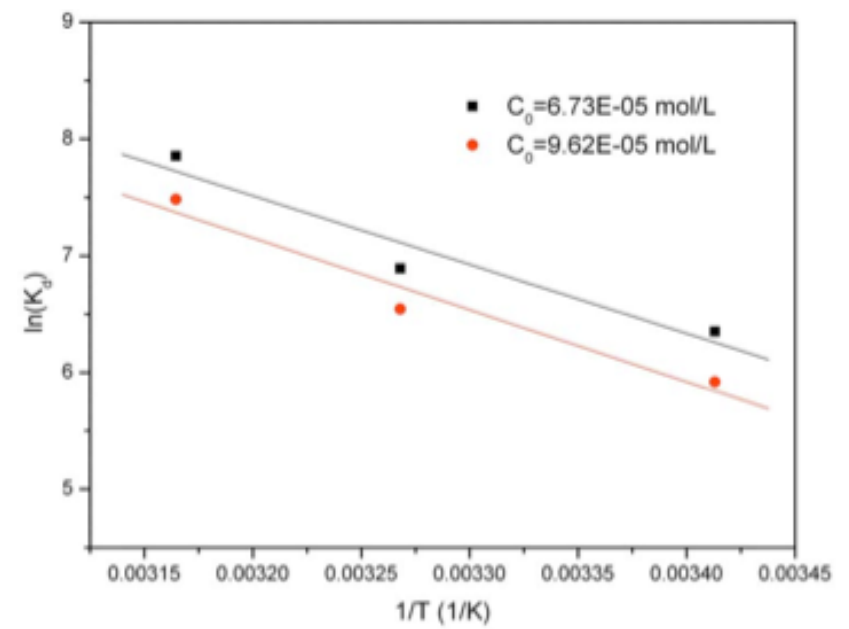

Fig. (8). Plot of distribution coefficient $K_{\mathrm{d}}$ vs. temperature for $\mathrm{Cr}(\mathrm{VI})$ adsorption on the raw MWCNTs. $\mathrm{I}=0.01 \mathrm{M} \mathrm{NaClO}_{4}$, $\mathrm{m} / \mathrm{V}=1.0 \mathrm{~g} / \mathrm{L}, \mathrm{pH}=2.88 \pm 0.02$.

\section{Thermodynamics Data}

The thermodynamic parameters calculated from Eqs. (12) and (13) are tabulated in Table 2. The values of $\Delta H^{\circ}$ and $\Delta S^{\circ}$ are calculated from the plots of $\ln K_{d}$ versus $1 / \mathrm{T}$ (Fig. 8). One can see that the $\Delta H^{\circ}$ values are positive, indicating the endothermic nature of the adsorption process. Positive values of $\Delta S^{\circ}$ suggest the increased randomness at the solid-solution interface. Negative values of $\Delta G^{\circ}$ confirm the adsorption process is spontaneous, which becomes more negative with an increase in temperature. This indicates that a higher adsorption is actually occurred at higher temperatures [33]. At higher temperature, ions are readily desolvated and thereby their adsorption becomes more favorable [15]. The $\Delta G^{\circ}$ values are more negative at low initial concentration than those at high initial concentration, which also confirms the more efficient adsorption at low initial concentrations.

\section{CONCLUSIONS}

In the light of the finding in this work, the following conclusions can be stressed:

The hydroxyl groups on the surfaces of MWCNTs exhibit amphoteric behavior and undergo the protonation reactions at low $\mathrm{pH}$ and the deprotonation reactions at high $\mathrm{pH}$. The $\mathrm{pH}_{\mathrm{pzc}}$ value of the raw MWCNTs is determined to be $\sim 4.3$ from the acidbase titrations.

The adsorption of $\mathrm{Cr}(\mathrm{VI})$ on MWCNTs is strongly dependent on temperature and $\mathrm{pH}$ values. The removal percentage of $\mathrm{Cr}(\mathrm{VI})$ increases with increasing temperature and decreases with increasing $\mathrm{pH}$ values.

The removal of $\mathrm{Cr}(\mathrm{VI})$ is mainly dominated by adsorption of $\mathrm{Cr}(\mathrm{VI})$ on MWCNTs. The surface adsorbed $\mathrm{Cr}$ (VI) can be reduced to $\mathrm{Cr}$ (III) on the surfaces of MWCNTs, and part of Cr(III) is released to solution in the adsorption process of $\mathrm{Cr}(\mathrm{VI})$ at low $\mathrm{pH}$ values. The XPS analysis indicates that the adsorbed $\mathrm{Cr}$ on MWCNTs are present as $\mathrm{Cr}(\mathrm{III})$ and $\mathrm{Cr}(\mathrm{VI})$ forms.

The oxidized MWCNTs show higher capacity for the adsorption of $\mathrm{Cr}(\mathrm{VI})$ than the raw MWCNTs. Considering the oxidation process, the raw MWCNTs can be used directly in the removal of $\mathrm{Cr}$ (VI) from aqueous solution.

(v) The adsorption of $\mathrm{Cr}(\mathrm{VI})$ on MWCNTs can be simulated well with Langmuir, Freundlich and D-R isotherm models. Assuming the batch adsorption to be a single-staged equilibrium operation, the separa- 
tion process can be defined mathematically using the Langmuir isotherm constants to estimate the residual concentration of $\mathrm{Cr}(\mathrm{VI})$ or amount of adsorbent for desired purification.

(vi) MWCNTs are suitable in the preconcentration and solidification of $\mathrm{Cr}(\mathrm{VI})$ from aqueous solutions because of the high stable properties at acidic conditions.

\section{ACKNOWLEDGEMENT}

Financial supports from Natural Science Foundation of China (20677058, J0630962) and 973 project (2007CB936602) are acknowledged.

\section{REFERENCES}

[1] Di ZC, Ding J, Peng XJ, Li YH, Luan ZK, Liang J. Chromium adsorption by aligned carbon nanotubes supported ceria nanoparticles. Chemosphere 2006; 62: 861-5.

[2] Di Natale F, Lancia A, Molino A, Musmarra D. Removal of chromium ions form aqueous solutions by adsorption on activated carbon and char. J Hazard Mater 2007; 145: 381-90.

[3] Khezami L, Capart R. Removal of chromium(VI) from aqueous solution by activated carbons: Kinetic and equilibrium studies. J Hazard Mater 2005; 123: 223-31.

[4] Lazarids NK, Asouhidou DD. Kinetics of sorptive removal of chromium(VI) from aqueous solutions by calcined $\mathrm{Mg}-\mathrm{Al}-\mathrm{CO}_{3}$ hydrotalcite. Water Res 2003; 37: 2875-82.

[5] Fang J, Gu ZM, Gang DC, Liu CX, Ilton ES, Deng BL. Cr(VI) removal from aqueous solution by activated carbon coated with quaternized Poly(4-vinylpyridine). Environ Sci Technol 2007; 41: 4748-53

[6] Periasam K, Srinivasan K, Murugan PR. Studies on chromium(VI) removal by activated ground-nut husk carbon. Indian J Environ Health 1991; 33: 433-9.

[7] Chand S, Agarwai VK, Pavankumar C. Removal of hexavalent chromium from wastewater by adsorption. J Environ Health 1994; 36: 151-8.

[8] Dakiky M, Khamis M, Manassra A, Mer'eb M. Selective adsorption of chromium (VI) in industrial wastewater using low-cost abundantly available adsorbents. Adv Environ Res 2002; 6: 533-40.

[9] Guo YP, Yang SF, Yu KF, Wang ZC, Xu HD. Adsorption of $\mathrm{Cr}(\mathrm{VI})$ on micro- and mesoporous rice husk-based active carbon. Mater Chem Phys 2002; 78: 132-7.

[10] Iijima S. Helical microtubules of graphitic carbon. Nature 1991; 354: 56-8.

[11] Zhou QX, Wang WD, Xiao JP, et al. Comparison of the enrichment efficiency of multiwalled carbon nanotubes, C18 silica, and activated carbon as the adsorbents for the solid phase extraction of atrazine and simazine in water samples. Microchim Acta 2006; 152: $215-24$

[12] Li Y, Wang S, Cao A, et al. Adsorption of fluoride from water by amorphous alumina $s$ upported on carbon nanotubes. Chem Phys Lett 2001; 350: 412-6.

[13] Long RQ, Yang RT. Carbon nanotubes as superior sorbent for dioxin removal. J Am Chem Soc 2001; 123: 2058-9.

[14] Liang P, Liu Y, Guo L. Determination of trace rare earth elements by inductively coupled plasma atomic emission spectrometry after preconcentration with multiwalled carbon nanotubes. Spectrochim Acta 2005; 60: 125-9.

[15] Chen CL, Wang XK. Adsorption of Ni(II) from Aqueous solution using oxidized multiwall carbon nanotubes. Indian Eng Chem Res 2006; 45: 9144-9.

[16] Wang XK, Chen CL, Hu WP, Ding AP, Xu D, Zhou X. Sorption of 243Am(III) to Multi-wall carbon nanotubes. Environ Sci Technol 2005; 39: 2856-60.

[17] Chen CL, Li XL, Zhao DL, Tan XL, Wang XK. Adsorption kinetic, thermodynamic and desorption studies of Th(IV) on oxidized multi-wall carbon nanotubes. Colloid Surf A 2007; 302: 449-54.

[18] Langmuir I. The adsorption of gases on plane surface of glass, mica and platinium. J Am Chem Soc 1918; 40: 1361-403.

[19] Zhang HG, Ritchie IM, Brooy SRL. The adsorption of gold thiourea complex onto activated carbon. Hydrometallurgy 2004; 72: 291-301.

[20] Özacar M, Şengil İA. Adsorption of reactive dyes on calcined alunite from aqueous solutions. J Hazard Mater 2003; 98: 211-24.

[21] Shahwan T, Erten HN. Temperature effects in barium sorption on natural kaolinite. J Radioanal Nucl Chem 2004; 260: 43-8.

[22] Aksoyoglu S. Sorption of U(VI) on granite. J Radioanal Nucl Chem 1989; 134: 393-403.

[23] Özcan A, Öncu EM, Özcan AS. Kinetics, isotherm and thermodynamic studies of adsorption of Acid Blue 193 from aqueous solutions onto natural sepiolite. Colloids Surf A 2006; 277: 90-7.

[24] Xu D, Tan XL, Chen CL, Wang XK. Adsorption of $\mathrm{Pb}(\mathrm{II})$ from aqueous solution to MX-80 bentonite: Effect of $\mathrm{pH}$, ionic strength, foreign ions and temperature. Appl Clay Sci 2008; 41: 37-46.

[25] Xu D, Chen CL, Tan XL, Hu J, Wang XK. Sorption of Th(IV) on Na-rectorite: Effect of HA, ionic strength, foreign ions and temperature. Appl Geochem 2007; 22: 2892-906.

[26] Weng $\mathrm{CH}$. Modeling $\mathrm{Pb}$ (II) adsorption onto sandy loam soil. J Colloid Interface Sci 2004; 272: 262-70.

[27] Li YH, Wang SG, Luan ZK, et al. Adsorption of cadmium(II) from aqueous solution by surface oxidized carbon nanotubes. Carbon 2003; 41: 1057-62.

[28] Li YH, Luan ZK, Xiao X, Ding J, Xu CL, Wu DH. Removal of $\mathrm{Cu}^{2+}$ ions from aqueous solutions by carbon nanotubes. Adsorpt $\mathrm{Sci}$ Technol 2003; 21: 475-85

[29] Hu J, Chen GH, Lo IMC. Removal and recovery of $\mathrm{Cr}(\mathrm{VI})$ from wastewater by maghemite nanoparticles. Water Res 2005; 39: 4528-36.

[30] Park SJ, Jang YS. Pore structure and surface properties of chemically modified activated carbons for adsorption mechanism and rate of Cr(VI). J Colloid Interf Sci 2002; 249: 458-63.

[31] Cimino G, Passerini A, Toscano G. Removal of toxic cations and $\mathrm{Cr}(\mathrm{VI})$ from aqueous solution by hazelnut shell. Water Res 2000; 34: 2955-62.

[32] Chen CL, Li XL, Wang XK. Application of oxidized multi-wall carbon nanotubes for Th(IV) adsorption. Radiochim Acta 2007; 95: 261-6.

[33] Yavuz Ö, Altunkaynak Y, Güzel F. Removal of copper, nickel, cobalt and manganese from aqueous solution by kaolinite. Water Res 2003; 37: 948-52.

(C) Hu et al.; Licensee Bentham Open.

This is an open access article licensed under the terms of the Creative Commons Attribution Non-Commercial License (http://creativecommons.org/licenses/by-nc/3.0/) which permits unrestricted, non-commercial use, distribution and reproduction in any medium, provided the work is properly cited. 